\title{
Evidence for the effectiveness of the Montreal Protocol to protect the ozone layer
}

\author{
J. A. Mäder ${ }^{1}$, J. Staehelin ${ }^{1}$, T. Peter ${ }^{1}$, D. Brunner ${ }^{2}$, H. E. Rieder ${ }^{1}$, and W. A. Stahel ${ }^{3}$ \\ ${ }^{1}$ Institute for Atmospheric and Climate Science, ETH Zurich, 8092 Zurich, Switzerland \\ ${ }^{2}$ Empa, Swiss Federal Institute for Materials Science and Technology, Duebendorf, Switzerland \\ ${ }^{3}$ Seminar for Statistics, ETH Zurich, 8092 Zuerich, Switzerland
}

Received: 18 June 2010 - Published in Atmos. Chem. Phys. Discuss.: 11 August 2010

Revised: 29 November 2010 - Accepted: 6 December 2010 - Published: 22 December 2010

\begin{abstract}
The release of man-made ozone depleting substances (ODS, including chlorofluorocarbons and halons) into the atmosphere has led to a near-linear increase in stratospheric halogen loading since the early 1970s, which levelled off after the mid-1990s and then started to decline, in response to the ban of many ODS by the Montreal Protocol (1987). We developed a multiple linear regression model to test whether this already had a measurable effect on total ozone values observed by the global network of groundbased instruments. The model includes explanatory variables describing the influence of various modes of dynamical variability and of volcanic eruptions. In order to describe the anthropogenic influence a first version of the model contains a linear trend (LT) term, whereas a second version contains a term describing the evolution of Equivalent Effective Stratospheric Chlorine (EESC). By comparing the explained variance of these two model versions we evaluated, which of the two terms better describes the observed ozone evolution. For a significant majority of the stations, the EESC proxy fits the long term ozone evolution better than the linear trend term. Therefore, we conclude that the Montreal Protocol has started to show measurable effects on the ozone layer about twenty years after it became legally binding.
\end{abstract}

\section{Introduction}

Stratospheric ozone depletion by chlorine radicals was first discussed by Stolarski and Cicerone (1974) and Molina and Rowland (1974). The latter also discovered that man-made chlorofluorocarbons (CFCs) act as a source for stratospheric chlorine. The full extent of anthropogenic ozone destruc-

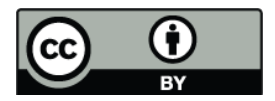

Correspondence to: J. A. Mäder (joerg.maeder@env.ethz.ch) tion became evident when the Antarctic ozone hole was discovered (Farman et al., 1985), which was subsequently explained as caused by ozone depleting substances (ODS) including CFCs and halons, their degradation products and a complex chemistry involving heterogeneous reactions on the cold surfaces of polar stratospheric clouds and aerosols (e.g. Solomon et al., 1987; Peter, 1997; Solomon, 1999). At northern mid-latitudes, significant negative trends in wintertime total ozone were first documented by the International Ozone Trends Panel (WMO, 1989). Many further studies confirmed a significant decrease in the thickness of the extratropical ozone layer (e.g. Staehelin et al., 2001, 2002; Fioletov et al., 2002; WMO, 2003, 2007).

An efficient reduction of the global anthropogenic emissions of ODS was reached by the Montreal Protocol (1987) and its subsequent Amendments (WMO, 2007). This was confirmed by long-term measurements of selected CFCs at remote ground stations (Montzka et al., 1996) as well as by balloon-borne measurements in the stratosphere (Engel et al., 2002). The successful implementation of the Montreal Protocol (e.g. WMO, 2007) launched a discussion on forthcoming ozone recovery in the second half of this century and a potential subsequent super-recovery by greenhouse gasinduced cooling of the upper stratosphere and a predicted increase in the Brewer-Dobson circulation as a result of climate change (e.g. Butchart and Scaife, 2001; Newchurch et al., 2003; Krizan et al., 2005; Austin and Wilson, 2006; Butchart et al., 2006; Eyring et al., 2007; Harris et al., 2008; Shepherd, 2008; Hegglin and Shepherd, 2009; Li et al., 2009; McLandress and Shepherd, 2009; Waugh et al., 2009). However, results of numerical simulations published by Hegglin and Shepherd (2009) predicted remarkable differences in the evolution of the ozone layer in the Northern and the Southern Hemisphere within the current century. Their results show that column ozone is expected to increase in the Northern Hemisphere all the way to the pole, while for the Southern

Published by Copernicus Publications on behalf of the European Geosciences Union. 
Hemisphere the increase is restricted to mid-latitudes and a decrease is predicted for the polar region due to decreased downwelling in Southern Hemisphere spring.

Several other studies (e.g., Prather et al., 1996; Velders et al., 2008; Morgenstern et al., 2008; Newman et al., 2009) reported on the positive effect of the Montreal Protocol, relating the expected development to "the world avoided", had the Montreal Protocol not been ratified. As its successful ratification prohibited the steady increase in the atmospheric burden of ODS, very severe ozone depletion and subsequent increase in erythemal UV were avoided.

Depending on their physico-chemical properties, individual ODS have different potentials to deplete stratospheric ozone. Equivalent Effective Stratospheric Chlorine (EESC) is a convenient quantity to characterize the ozone depletion potentials of halogens (chlorine and bromine) taking into account the temporal evolution of the emissions of the individual species, their transport into the stratosphere and their atmospheric lifetimes (WMO, 2007). ${ }^{1}$ Since air is transported from the tropical troposphere into the stratosphere, and then takes a few years from the tropical entry point before reaching high latitudes (Newman et al., 2007), an additional lag of 2.5 years applies when using EESC to describe the polar latitudes. Between the early 1970s and the mid-1990s EESC increased in an almost linear way (see Fig. 1). EESC peaked in 1997, several years after the peak in emissions, due to the long transport time to reach the ozone layer and the long atmospheric lifetimes of ODS. This was confirmed by ground based Fourier Transform Infrared Reflectance (FTIR) measurements at Jungfraujoch (Switzerland) of column amounts of the stratospheric reservoir species hydrogen chloride $(\mathrm{HCl})$, which is formed by the reaction of methane $\left(\mathrm{CH}_{4}\right)$ with chlorine radicals released by the stratospheric photolysis of CFCs (black solid line in Fig. 1). These findings suggest that the slow recovery of the ozone layer over mid-latitudes may have started at the earliest in the late 1990s (Rinsland et al., 2003).

The bulk of stratospheric ozone resides in the lower and middle stratosphere. At these altitudes extra-tropical ozone is highly variable and therefore the effect of the Montreal Protocol on total ozone is much more difficult to identify there than in the upper stratosphere (e.g. Weatherhead et al., 2000). Reinsel and colleagues (2002) estimated that the detection of the first stage of ozone recovery (defined as a deviation from a linear decrease) requires about 7-8 years of total ozone observations after the onset of the recovery. Recent studies provide growing evidence that a weakening or even rever-

\footnotetext{
${ }^{1}$ Here we use the EESC definition given by the WMO EESC A1_2010A scenario in which the fractional release types are from Newman et al. (2007) available from http://acdb-ext.gsfc.nasa.gov/ Data_services/automailer using the following parameters: mean age of air: 3.0 years; width of age of air spectrum: 1.5 years; fractional release rate for each species $\left(\mathrm{Cl}_{\mathrm{y}}, \mathrm{Br}_{\mathrm{y}}, \mathrm{F}_{\mathrm{y}}\right)$; bromine scaling factor: 60.
}

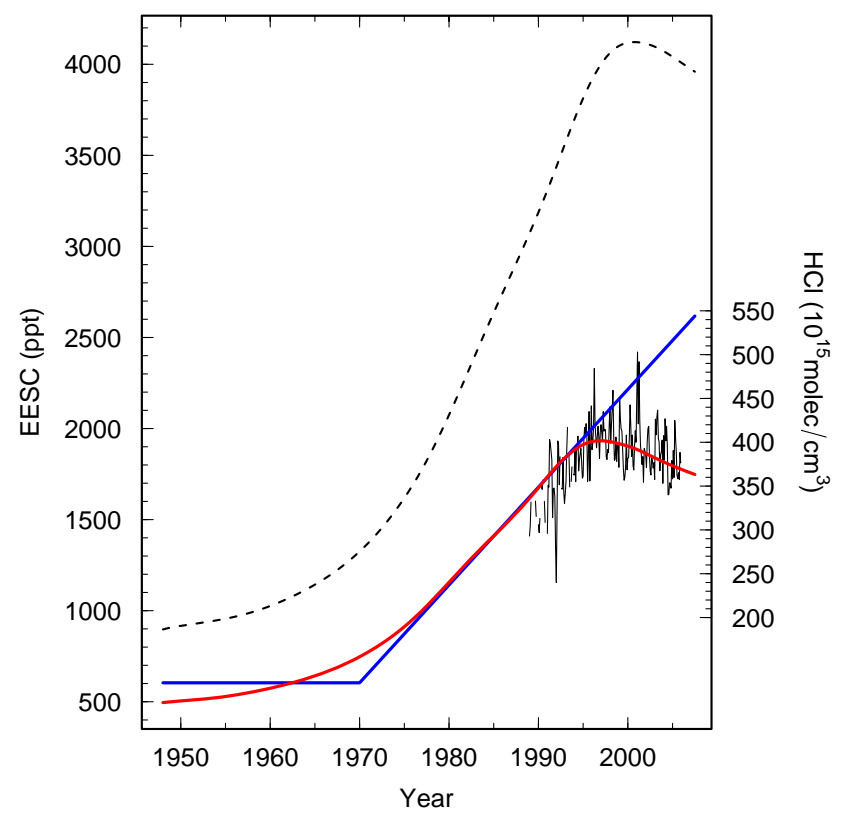

Fig. 1. Left axis: Time series of Equivalent Effective Stratospheric Chlorine (EESC) for extra-polar latitudes (red line) and linear trend (LT) as used in many previous studies (blue line). Right axis: time series of ground-based $\mathrm{HCl}$ columns measured at Jungfraujoch (Switzerland, $3580 \mathrm{~m}$ a.s.l., black solid line). For polar stations the same EESC and LT curves are used, but applying an additional time lag of 2.5 years (Newman et al., 2007). The black dashed curve shows EESC using 5.5 years as mean age-of-air values, instead of 3 years.

sal of the negative ozone trends may already be detectable (Newchurch et al., 2003; Guillas et al., 2004; Steinbrecht et al., 2004; Reinsel et al., 2005; Yang et al., 2005, 2006; Brunner et al., 2006; Weatherhead and Anderson, 2006; WMO, 2007; Harris et al., 2008). Increases in total ozone since the early 1990s have been noted at several sites in the northern mid-latitudes, but the attribution of these changes to EESC is a difficult task (Yang et al., 2006), because several factors may have contributed to an apparent flattening or reversal in ozone tendencies. These may include: (i) changes in synoptic scale meteorological variability and long-term climate variability (e.g. Hood and Zaff, 1995; Steinbrecht et al., 1998; Appenzeller et al., 2000; Thompson an Wallace, 2000; Orsolini and Doblas-Reyes, 2003; Brönnimann and Hood, 2003; Shepherd et al., 2008; Rieder et al., 2010); (ii) the large volcanic eruption of Mount Pinatubo in 1991 leading to record low values in the following two years (e.g. Gleason et al., 1993; Rosenfield et al., 1997; Robock, 2000; Yang et al., 2005; Brunner et al., 2006; WMO, 2007); (iii) the maximum in solar activity in 2001 (Steinbrecht et al., 2004); and (iv) particularly cold winters with enhanced polar ozone loss in the Arctic during the mid 1990s and in the Antarctic in 2006 with one of the largest austral ozone holes ever (WMO, 2006). 
Numerical simulations have been performed in order to describe in a quantitative way the effect of anthropogenic emissions of ODS on the stratospheric ozone layer. During the last decade a number of three dimensional models have been developed aiming at describing the complex interactions of stratospheric chemistry and transport allowing climatic changes to be taken into account (e.g. WMO, 2007). Nevertheless, the validation of these models regarding their capability to adequately describe all relevant processes and hence to reliably predict the evolution of stratospheric ozone remains a challenging task given all inter-model differences and different parametrizations (Eyring et al., 2007, 2010; Austin et al., 2010a, b; SPARC-CCMVal, 2010).

Previous studies reported that "simple" linear trends were inadequate to characterize the long-term behavior of column ozone due to the stabilization in recent years (e.g., Reinsel, 2002; Reinsel et al., 2002; Newchurch et al., 2003). Within these studies the so-called CUMSUM method, i.e. the difference of the cumulative sum of residuals from a linear trend, was applied to show that the ozone loss rate has diminished. Here we use a statistical test as a complementary method to provide evidence for the effectiveness of the Montreal Protocol. The basic concept of the approach is simple: We test whether the temporal evolution of total ozone measurements can be better described by a linear trend (LT, starting on 1 January 1970, as expected without the regulation by the Montreal Protocol), or by the evolution of EESC (reflecting the regulation; see Fig. 1). The test itself consists of fitting these two model versions to 116 station series and performing a binomial test with a probability of $50 \%$ (also known as sign-test) on the number of stations for which EESC provides a better result. The model includes additional explanatory variables describing other (natural) influences, which are selected, as a first step, by backward elimination methods.

\section{Methods and Measurements}

\subsection{Multiple linear regression models and selection of explanatory variables}

We used the following multiple regression model

$\mathrm{TOZ}=M+b_{1} \cdot$ Trend $+\sum_{j=2}^{m} b_{j} \cdot X_{j}+\varepsilon$,

where TOZ is the measured total ozone monthly mean value at a single station, $M$ is the seasonal variation of total ozone described by individual values for each month (to represent the seasonal cycle), Trend is either EESC or LT, $b_{1}$ the trend coefficient, $X_{j}$ are other explanatory variables and $b_{j}$ their respective coefficients (see Table 1 and text below). The residual errors are described by $\varepsilon$. The autocorrelation (in time) is not taken into account in either version (using EESC or LT). However, autocorrelation is expected to not affect the results of our comparative analysis, as it should affect both versions in the same way.
The independent variables (or so-called "explanatory variables") included in the analysis have been selected according to the results of Mäder et al. (2007). The applied backward elimination approach consists of multiple steps. First, for each station, a sequence of elimination for 44 potential explanatory variables is determined by applying stepwise backward elimination based on the p-values of the regression coefficients. This sequence defines a rank for each variable at each station. The ranks are then averaged over all stations in a given geographical zone, and the variable with the lowest rank is dropped from the set of potential explanatory variables. Then, the ranking step for each station is restarted with the remaining 43 variables. This procedure is repeated until only one variable is left, leading to a ranking table for each geographical zone (North Polar, Northern Midlatitudes, Tropics, Southern Mid-latitudes, South Polar). The final model for each zone includes only the highest ranking variables. Its size is determined by the number of significant variables and the explained variance $\left(R^{2}\right)$ as described in Mäder et al. (2007).

In the next stage, the resulting model was fitted twice for each station in the zone, including the two versions (EESC or LT) of the trend, and the coefficients of determination $R^{2}$ were calculated and compared, resulting in a preference of either EESC or LT for each station. Then we calculate for the different zones if a significant part of the stations show the same preference, according to the sign-test.

While this approach is qualitative in nature, it is robust and avoids the selection of a fixed point in time for the turnaround (Percival and Rothrock, 2005), as was required in other studies (Reinsel et al., 2002, 2003; Newchurch et al., 2003; Yang et al., 2005, 2006; Weatherhead and Anderson, 2006).

\subsection{Statistical tests}

Since the geographical distances between some of the ground-based stations are small, their preference for either EESC or LT may not be independent because of spatial correlations of the measurements. Therefore, we tested the spatial correlation of our results as expressed by the following transformed difference $T$ between the explained variances:

$T=\operatorname{sign}\left(R_{\mathrm{EESC}}^{2}-R_{\mathrm{LT}}^{2}\right) \cdot \sqrt{\left|R_{\mathrm{EESC}}^{2}-R_{\mathrm{LT}}^{2}\right|}$

where $R_{\mathrm{EESC}}^{2}$ and $R_{\mathrm{LT}}^{2}$ are the explained variances of the model using either EESC or LT. (We used the square root transformation since a normal distribution is an important requirement for spatial analysis and the distribution of $T$ is, in contrast to the simple difference, very close to it.) For the calculation of the spatial correlation of $T$ we used the estimator by Cressie and Hawkins (1980). Pairwise differences between the T-values of all stations are grouped into distance 
Table 1. Regression model for total ozone (TOZ) of the five latitude belts (see Mäder et al., 2007) as selected by the procedure described in the text. If not yet present, a seasonal trend term (seas:Trend) was added for this study (SM and SP). The sequence of the explanatory variables reflects their ranks determined in the model selection procedure. The variable $M$ (=month) represents the residual seasonal cycle; EL, the equivalent latitude proxy; Trend is either EESC or LT; $T_{X}$, the temperature at pressure level $X$; $\mathrm{PV}_{X}$, the potential vorticity at potential temperature level $X$; SAD, the vertically integrated aerosol surface area density (describing the influence of volcanic eruptions); $V_{\mathrm{PSC}}$, the cumulative volume of polar stratospheric clouds (describing polar ozone depletion); $\mathrm{QBO}_{X}$ the quasi-biennial oscillation at pressure level $X$. $M$ is represented by 12 values. The notation seas:Trend indicates that different coefficients for Trend are estimated for each of the seasons (4 values). The other variables are characterized by a single (annual-mean) coefficient.

\begin{tabular}{ll}
\hline Latitude belt & Optimized Version of Regression Model \\
\hline $\begin{array}{l}\text { North Polar (NP): } \\
11 \text { stations north of } 62^{\circ} \mathrm{N}\end{array}$ & $\mathrm{TOZ} \sim \mathrm{EL}+M+$ seas: Trend $+V_{\mathrm{PSC}}+T_{50}+\mathrm{SAD}$ \\
$\begin{array}{l}\text { Northern Mid-latitude }(\mathrm{NM}): \\
65 \text { stations } 33^{\circ} \mathrm{N}-62^{\circ} \mathrm{N}\end{array}$ & $\mathrm{TOZ} \sim \mathrm{EL}+M+T_{10}+$ seas: Trend $+\mathrm{SAD}$ \\
$\begin{array}{l}\text { Tropical (TR): } \\
27 \text { stations } 30^{\circ} \mathrm{S}-33^{\circ} \mathrm{N}\end{array}$ & $\mathrm{TOZ} \sim \mathrm{EL}+M+$ seas: Trend \\
Southern Mid-latitude $(\mathrm{SM}):$ & $\mathrm{TOZ} \sim \mathrm{EL}+T_{50}+\mathrm{QBO}_{30}+M+$ seas: Trend \\
7 stations $60^{\circ} \mathrm{S}-30^{\circ} \mathrm{S}$ & $\mathrm{TOZ} \sim \mathrm{PV}_{470}+$ seas: Trend $+\mathrm{EL}+M+T_{50}$ \\
South Polar $(\mathrm{SP}):$ & \\
6 stations south of $60^{\circ} \mathrm{S}$ & \\
\hline
\end{tabular}

classes $C(h)$. Typically about 10 to 30 classes are used. Based on these differences the semivariance $s_{h}$ is defined as

$s_{h}=\frac{\left(\frac{1}{n_{C(h)}} \sum_{(i, j) \in h} \sqrt{\left|T_{i}-T_{j}\right|}\right)^{4}}{0.914+\frac{0.988}{n_{C(h)}}}$

where $n_{C(h)}$ is the number of pairs of stations in this distance class. Graphs of $s_{h}$ vs. $h$ show the structure of the spatial correlation. In case of significant spatial correlations, $s_{h}$ increases with $h$. Often the increase is restricted to short distances and $s_{h}$ remains constant above a certain distance called range. Above this range, the individual stations are no longer correlated (Cressie, 1993). In our analysis, we calculated the spatial correlation separately for the zones defined as northern, southern and tropical latitude belt as well as for all stations together (see Sect. 3.1).

The test on the preference of either EESC or LT on zonal level is of simple form as only the sign of $T$ (Eq. 2, positive EESC preference, negative LT preference) at the single stations is used in the binominal test. Consequently, significance is only considered over all stations within a zonal band and not on the level of individual stations. For illustration purposes the test values $T$ are used in Figs. 2, 4, and 5.

\subsection{Total ozone measurements used in this study}

For the ozone time series we used the ground based stations provided by WOUDC (World Ozone and Ultraviolet Data Centre, Toronto, www.woudc.org, measurements up to March 2007 as available in May 2007) with sufficiently long time series (at least 120 monthly mean values and measurements beyond the year 2000). Available series are different in length. However, sensitivity analysis did not show any effect of record length on the test value $T$ (Fig. 2). Data before 1948 were not used, since the relevant proxies are not available for the time before 1948. However, this restriction affected only a few stations as most ozone time series started later. Ground based measurements were selected because at many stations, observation started in the 1960s or early 1970s, allowing to better fit the individual coefficients of the model (especially for slowly varying processes) than would be possible for satellite observations available since 1979. Data quality of ground based total ozone measurements is expected to be ensured by comparison with standard instruments. However, some total ozone records reported at WOUDC contain discontinuities partially because of technical problems (Fioletov et al., 2008). Parts of the records of stations showing obvious discontinuities were excluded after visual inspection. Under the assumption that data quality problems of individual stations are random, the conclusions drawn here will remain valid, and any further attempt to homogenize, improve or select certain data is inevitably connected with other problems or biases.

In total, 116 stations with 34'923 monthly total ozone values were used, which corresponds to an average of 23.5 years of data per station.

\section{Results and Discussion}

\subsection{Selected explanatory variables and spatial correlation}

The explanatory variables $X_{j}$ were selected by backward elimination (see Sect. 2.1), starting with a large set of different time series of possible variables. Table 1 shows the 


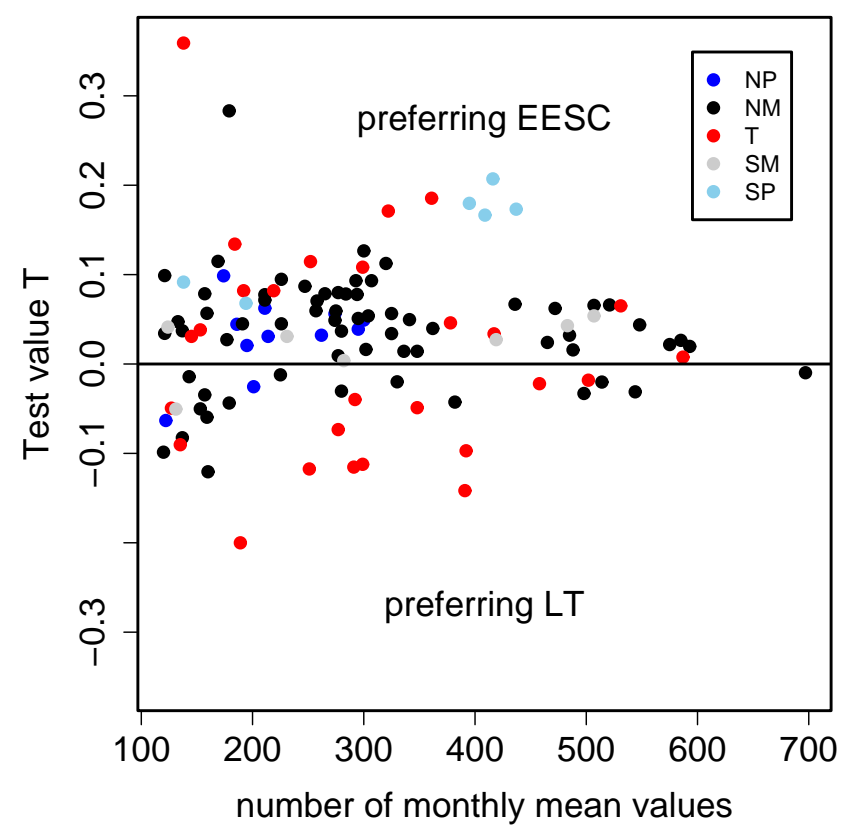

Fig. 2. Test value $T$ (see Eq. 2) against the number monthly mean data available for calculation. NP denotes Northern Polar belt, NM denotes Northern Mid-latitude belt, $T$ denotes tropics, SM denotes Southern Mid-latitude belt and SP denotes Southern Polar belt.

result and gives a short description of the selected variables. The variable of equivalent latitude (EL) was developed to describe the effect of dynamics on column ozone (Wohltmann et al., 2005). It is calculated in two steps. First, the potential vorticity $(\mathrm{PV})$ over a station at different potential temperature levels is mapped to the latitude, which encloses the same area as the PV contour. Second, the corresponding ozone profile is derived from the monthly climatology and vertically integrated. For further details we refer to Wohltmann et al. (2005). The EL was selected in all bands. It is known that changes in atmospheric dynamics contributed significantly to the past evolution of stratospheric ozone at different sites (e.g. Labitzke and van Loon, 1999; Chipperfield and Jones 1999; Appenzeller et al., 2000; Hadjinicolaou et al., 2002; Orsolini and Doblas-Reyes, 2003; Harris et al., 2008) and that the increase in total ozone found at northern mid-latitudes in the 1990s (Hood and Soukharev, 2005; Harris et al., 2008) is attributable to a large extent to changes in dynamics. The inclusion of EL in the model provides confidence that the main results of the study are not confused by changes in dynamics, since changes in transport are believed to be the main driver for the long-term evolution of the ozone shield besides ODS.

A large perturbation of stratospheric ozone was caused by the eruption of Mt. Pinatubo in 1991 close to the maximum of EESC. Since large volcanic eruptions led to lower total ozone values in the subsequent years (e.g. Randel et al., 1995; Hadjinicolaou et al., 1997), this may lead to a preference for
EESC over the linear trend. Based on the backward elimination procedure the variable SAD (vertically integrated Stratospheric Aerosol surface area Density) representing the effect of volcanic eruptions was identified as an important variable in the two northern latitude belts. In the Southern Hemisphere the influence of the past volcanic eruptions (e.g. Gunung Agung, 1963; El Chichón, 1982; Mt. Pinatubo, 1991) on column ozone could not be identified in similar strength as in the Northern Hemisphere. Robock et al. (2007) attempted to explain the hemispheric difference in the effect of volcanic eruptions by atmospheric dynamics, namely as the combination of the difference in land mass at the latitude of the jet stream and the stronger polar vortex in the Southern Hemisphere. The inclusion of SAD in the model distinctively reduces the residuals for the corresponding time period. Thus, in contrast to other studies (Reinsel et al., 2002; Yang et al., 2006) we apply the regression model including SAD to the complete ozone time series instead of removing a couple of years following the eruption of Mt. Pinatubo.

In earlier WMO assessments the Quasi Biennial Oscillation (QBO) and the eleven year solar cycle were used as explanatory variables in order to remove long-term variability in statistical trend models. They were not selected as important proxies for the long-term ozone evolution in our model selection procedure (comp. Mäder et al., 2007). Possibly some of the variability caused by QBO is captured by EL. The solar cycle is nevertheless included as explanatory variable in our sensitivity analysis presented in Sect. 3.2.

Model performance is addressed in the supplementary material, where the results for four sample stations are shown (one for the Northern mid-latitude and the Northern Polar belt preferring EESC, and one for the Northern mid-latitude and Tropics preferring LT).

Ground-based total ozone measurements are unevenly distributed over the globe, a substantial part of the monitoring sites being located in Europe. Spatial correlations between stations are studied since in their presence the basic testing approach would need a modification. As shown in Fig. 3, spatial correlation is only visible if all belts are used together (bottom right; global). But for the single belts no increase in $s_{h}$ even for small distances is visible, but rather, $s_{h}$ appears to stay constant (this situation is called a pure-nugget model and implies uncorrelated random deviations). Therefore we may assume that spatial correlation does not reduce the multitude of pieces of independent information in our test, as long as we analyze the three latitude belts separately.

\subsection{Long-term ozone evolution: linear trend vs. EESC}

After selection of the explanatory variables for each latitudinal belt, a test was used to study whether the measurements of the individual sites rather follow a linear trend or the time evolution of EESC (see introduction). A binomial test was used to determine whether the stations in a given latitude belt showed a significant preference for one of two the models. 


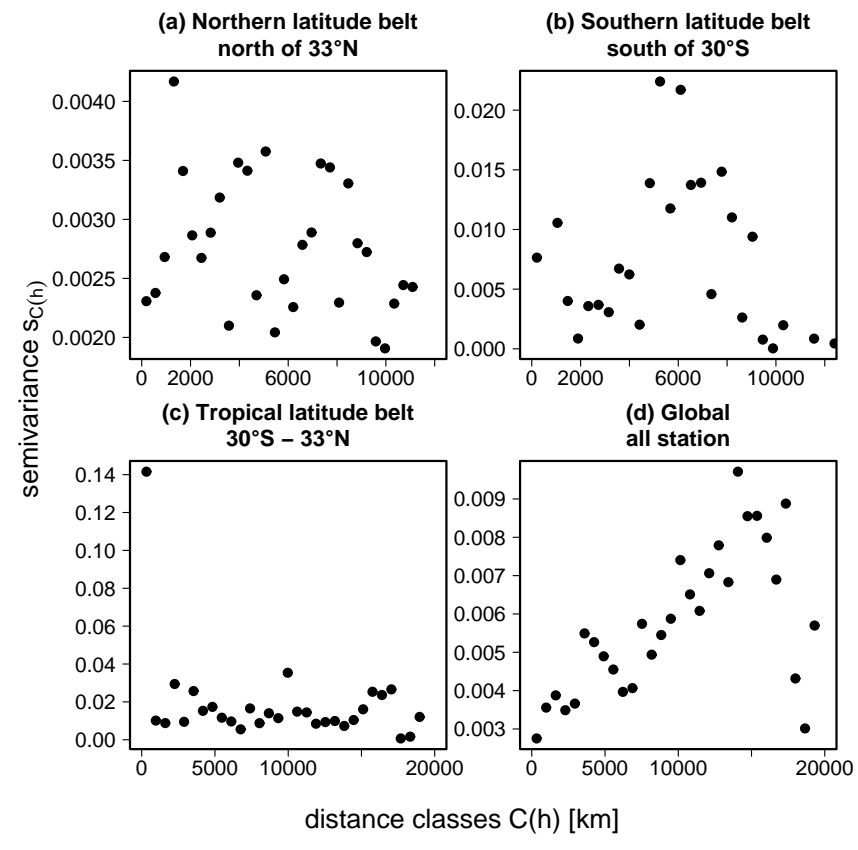

Fig. 3. Spatial variograms for the (a) northern, (b) southern, (c) tropical latitude belts and for (d) all stations together. In contrast to panel (d), panels (a) to (c) do not show an increase of semivariance with the distance. As a consequence, for the three latitude belts (ac), used each apart, the stations can be used without corrections for the sign-test. But this is not the case for the situation in panel (d) where all the three other belts are used together.

The use of this test is justified because no spatial correlation was found (see Sect. 3.1). The two northern latitude belts show a clear preference for EESC to describe the measured ozone evolution (see Fig. 4). The results are significant at the 5\% level (which corresponds to a 95\% confidence interval) individually as well as together. In the tropical latitude belt EESC and LT are nearly balanced. This result can be explained by the small trends compared to the high variation of total ozone. In the two southern latitude belts EESC is again preferred. The result of the southern mid-latitudes is not significant, probably because of the small number of stations. Note that the statistically significant result for the South Polar latitudes should be ignored, due to a "saturation" of the ozone loss in the Antarctic due to the presently large availability of ODS. In contrast, the situation in the Arctic is less dynamically driven (e.g. Solomon, 2007) and thus more strongly influenced by the present ODS levels, which justifies the interpretation of the results for this region in terms of reduced EESC.

In our analysis the last years are expected to be most relevant because the difference between EESC and LT increases with time (Fig. 1). To test the expected change in time, we repeated our analysis for different time windows. Figure 5 shows that the number of ozone series following EESC rather than LT increases with time, which supports the results. All regions besides Southern Polar (panel e), which should not be considered as mentioned before, start in the 1990s around zero, meaning undecided between EESC and LT. At the tropical stations this does not change over time (see panel c). The two Northern zonal belts (see panels a and b) show clear preference of EESC over LT from the late 1990s onwards. The picture for southern mid-latitudes (see panel d) is similar, but unfortunately, the number of stations is too small to derive a "clear" preference of EESC over LT.

In order to test the robustness of the results we performed a number of sensitivity studies (see Table 2). The last solar cycle which peaked in the year 2001 most likely contributed to the observed ozone increase in the uppermost stratosphere since the mid 1990s and hence to the apparent turnaround in total ozone (Steinbrecht et al., 2004; Dameris et al., 2006). Based on our elimination process, solar flux, described by the solar flux intensity at $10.7 \mathrm{~cm}$, is not one of the most important influence factors for total ozone (Mäder et al., 2007). Consequently, inclusion of solar flux in the equations does not affect our results significantly (see Table 2).

We tested also for a different EESC scenario by Newman et al. (2007) (with Mean of age-of-air: 5.5; Width of Ageof-Air Spectrum: 1.5 years; use of inorganics; EESC with $\alpha$ : 60) but this change did not affect the results (see Table 2, EESC 5.5. years). The robustness of the results was to be expected, since the different versions of EESC are nearly identical up to linear transformations, and such alterations do not affect the significance of a variable in multiple linear regression. As a last test we replaced the linear trend before 1992 by the shape of the EESC time series, therefore they only differ after 1992. Also this test did not show any notable differences in the results (see Table 2, Hybrid).

To conclude, our results are robust to several changes of the setup of the regression showing consistently that EESC better predicts the overall set of observations than a linear trend.

\section{Conclusions}

In the late 1970s and the 1980s, i.e. since the paper of Molina and Rowland (1974), the search for a significant downward trend of total ozone measurements was an important research topic in the debate whether it was justified to limit man-made ODS emissions. Statistical models were developed in which natural variability was removed by using the explanatory variables of Quasi-Biennial Oscillation and the eleven year solar cycle. Significant downward trends were first published in the Ozone Trend Panel report in 1989 (WMO, 1989) for northern mid-latitudes (where a large part of the human population lives). This was viewed as evidence that the stratospheric ozone layer had been diminished by man-made emissions of ODS. The Montreal Protocol (1987, including its enforcements in the subsequent years) has proved to be very effective to limit ODS emissions. More than twenty years 


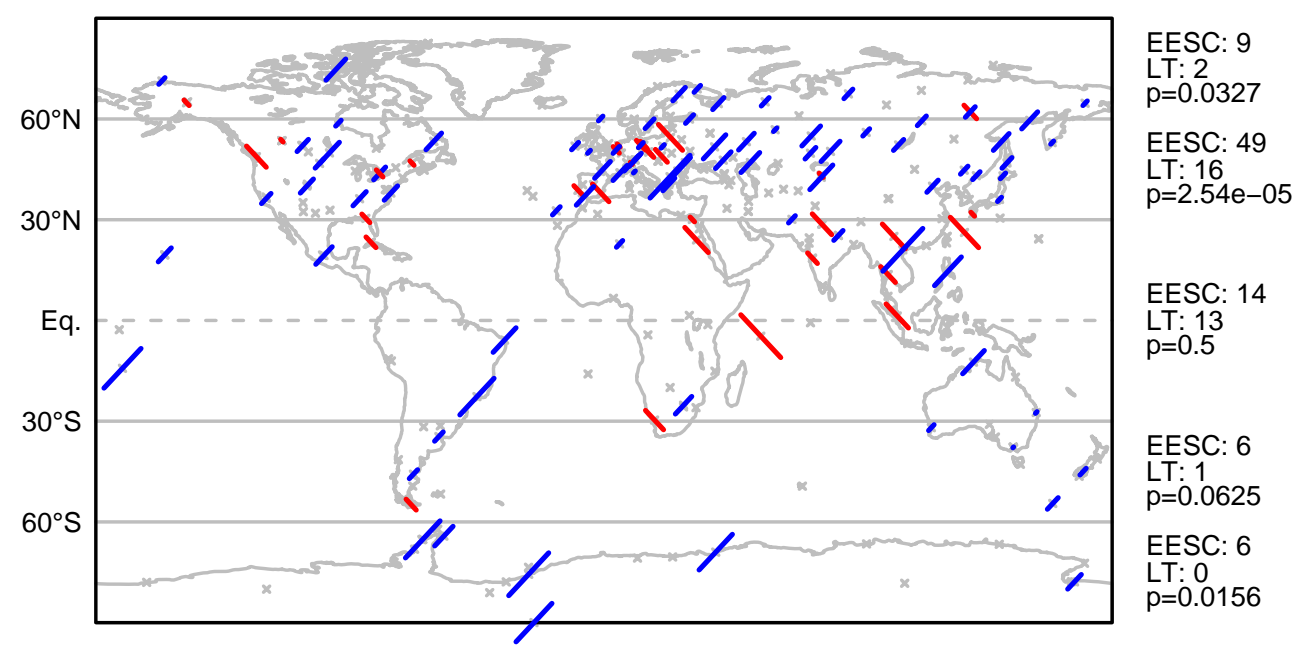

Fig. 4. Map of ground based stations used in this study. Stations preferring EESC over linear trend (see text and Fig. 1) are represented by blue lines and a positive slope, others with red lines and a negative slope. The length of the lines represents the absolute value of the test statistic $T$. For each latitude belt, the numbers of stations preferring EESC or LT are given on the right-hand side together with the p-value of the binomial test.
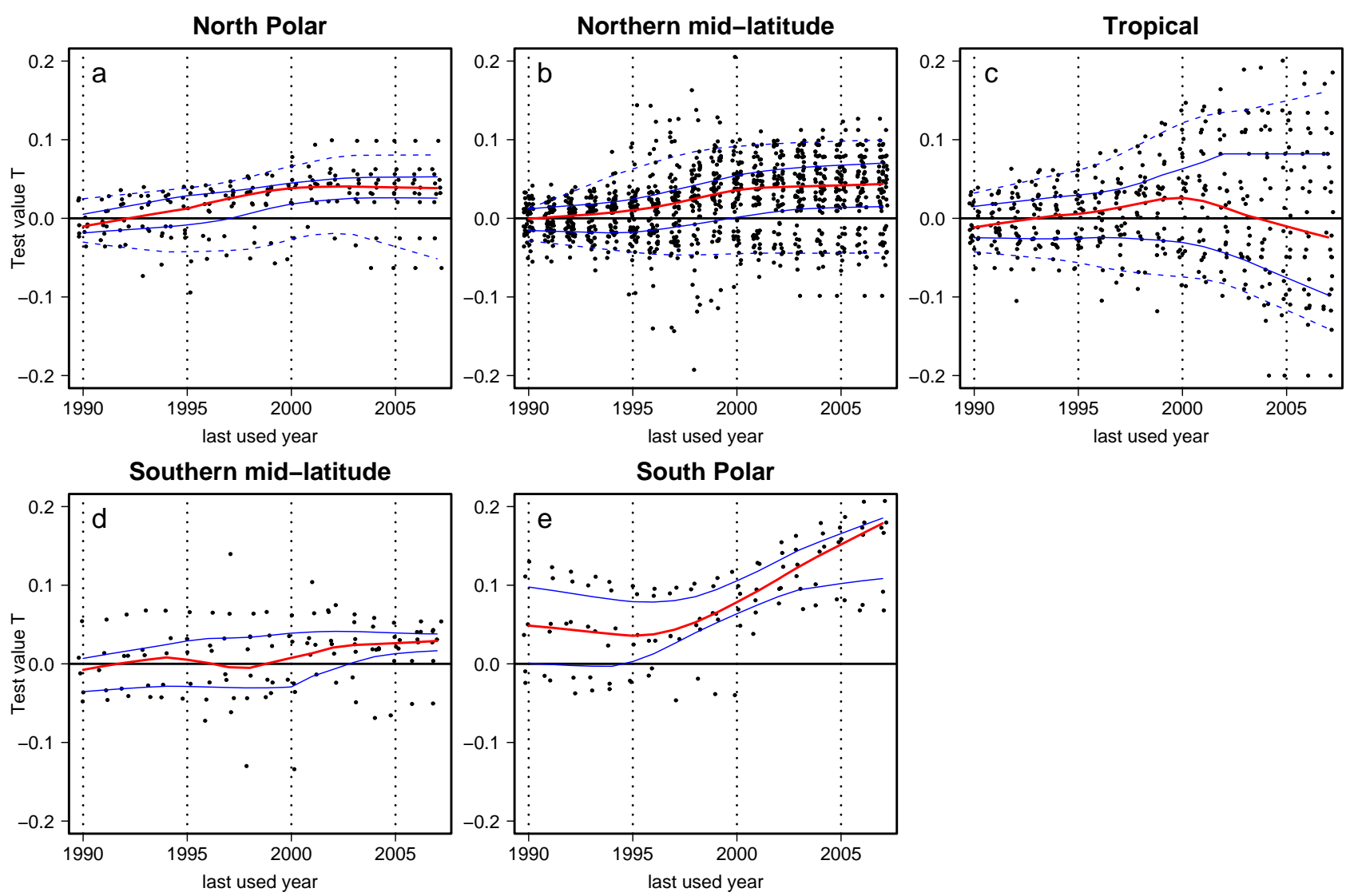

Fig. 5. Evolution of the test value $T$ with increasing time window for (a) North Polar, (b) Northern mid-latitude, (c) Tropical, (d) Southern mid-latitude and (e) South Polar. Single points represent the $T$ (test value of preference of EESC over LT, see Eq. 2) values for each station for an end point of the time window given by the value on the $\mathrm{x}$-abscissa. The points are jittered horizontally for better visibility. Coloured lines show LOWESS smoothed (with smoothing parameter $f=0.5$ ) quantiles (blue dashed 5\% and 95\%; blue solid 25\% and $75 \%$; red: $50 \%$ ). Due to few stations available at Southern latitudes the $5 \%$ and $95 \%$ quantile are not meaningful, and therefore not shown. 
Table 2. Number of stations preferring EESC over LT in different versions of the basic model. The column "Standard" corresponds to the main results of the paper. The column "All data" includes also the data from WOUDC that was classified unreliable (see Sect. 2.3). The fifth column refers to Sect. 3.2 on the influence of the solar cycle with solar flux at $10.7 \mathrm{~cm}$ as additional proxy. For the next column the new formulation for EESC by Newman et al. (2007) with an age-of-air of 5.5 years is used (instead of 3.0 years). The last column represents the results if linear trend was adapted to the shape of EESC before 1992.

\begin{tabular}{lrrrrrr}
\hline Region & $\begin{array}{r}\text { Number of } \\
\text { stations }\end{array}$ & Standard & All data & Solar Cycle & $\begin{array}{c}\text { EESC } \\
5.5 \text { years }\end{array}$ & Hybrid \\
\hline NP & 11 & 9 & 9 & 9 & 8 & 10 \\
NM & 65 & 49 & 49 & 45 & 52 & 50 \\
TR & 27 & 14 & 14 & 14 & 12 & 13 \\
SM & 7 & 6 & 6 & 5 & 6 & 6 \\
SP & 6 & 6 & 6 & 6 & 6 & 6 \\
\hline
\end{tabular}

later, the documentation of the beneficial effect of the Montreal protocol to protect the ozone layer is still not a simple task. One approach to this problem has been the use of 2- and 3-dimensional numerical models to describe the effect of reductions of ODS on the ozone layer. However, because of the complex interactions between transport and chemical processes (including e.g. heterogeneous processes on polar stratospheric clouds) and the limited computer resources such models need simplifications. Moreover, the validation against observations revealed widely varying degrees of success of the individual state-of-the-art models with respect to the reproduction of individual processes including the observed ozone evolution (e.g., Eyring et al., 2007, 2010; WMO, 2007; Austin et al., 2010a, b; SPARC-CCMVal, 2010). Because of this large model spread the results concerning the effect of changes in man-made ODS emissions versus changes in dynamics remained controversial.

A complementary approach to describing the effect of changes in the column ozone is the use of statistical modelling. The results of such an approach, however, do not provide direct causal relationship and only allow for a sound interpretation if the used proxies are directly linked to the determining processes, which is generally difficult to prove. The proxies EL, T50 and PV400 identified by the elimination procedure, for example, are not readily attributable to a specific dynamical process but rather represent the combined effect of several processes including wave activity at different levels, the residual circulation, and the quasi-biennial oscillation. The effect of man-made ODS emissions on chemical ozone depletion, on the other hand, is more directly represented by the parameter EESC.

The aim of the study is not to provide reliable quantitative numbers concerning the attribution of ozone layer changes to chemical depletion or dynamics. The goal is rather to show the effectiveness of the "Montreal Protocol for the Protection of the Ozone Layer". For this we compared two statistical ways to model the temporal evolution of the ozone layer, a linear upward trend (as a surrogate of the time evolution of the ozone layer without a Montreal Protocol) and the temporal evolution attributable to the observed evolution of ODS following the Montreal protocol (EESC). We argue that the dynamical proxies, in particular EL, can represent dynamical changes in a sufficient way not to confuse the discrimination between a linear trend and an EESC trend. Note that our results have to be viewed as qualitative analysis. However, because of their robustness we regard our results as clear and unprecedented evidence for the effectiveness of the Montreal Protocol for the protection of the ozone shield, proving the success of international cooperation between science, economy and politics.

\section{Supplementary material related to this article is available online at: http://www.atmos-chem-phys.net/10/12161/2010/ acp-10-12161-2010-supplement.pdf.}

Acknowledgements. J. M. and D. B. were supported by the EUprojects CANDIDOZ and SCOUT-O3 within Framework Program 6 of the European Commission. H. R. was supported by the Competence Centre for the Environment and Sustainability (CCES) within the ETH-domain in Switzerland within the project EXTREMES: "Spatial extremes and environmental sustainability: Statistical methods and applications in geophysics and the environment".

Data were provided by National Centers for Environmental Prediction (NCEP), European Center for Medium range Weather Forecasting (ECMWF), World Ozone and Ultraviolet Radiation Data Centre (WOUDC), National Aeronautics and Space Administration (NASA) and British Antarctic Survey (BAS).

Edited by: M. Dameris 


\section{References}

Appenzeller, C., Weiss, A. K., and Staehelin, J.: North Atlantic Oscillation modulates total ozone winter trends, Geophys. Res. Lett., 27, 1131-1134, 2000.

Austin, J. and Wilson, R. J.: Ensemble simulations of the decline and recovery of stratospheric ozone, J. Geophys. Res.-Atmos., 111, D16314, doi:10.1029/2005jd006907, 2006.

Austing, J., Scinocca, J., Plummer, D., Oman, L., Waugh, D., Akiyoshi, H., Bekki, S., Braesicke, P., Butchart, N., Chipperfield, M., Cugnet, D., Dameris, M., Dhomse, S., Eyring, V., Frith, S., Garcia, R. R., Garny, H., Gettelman, A., Hardiman, S. C., Kinnison, D., Lamarque, J. F., Mancini, E., Marchand, M., Michou, M., Morgenstern, O., Nakamura, T., Pawson, S., Pitari, G., Pyle, J., Rozanov, E., Shepherd, T. G., Shibata, K., Teyssedre, H., Wilson, R. J., and Yamashita, Y.: Decline and recovery of total column ozone using a multimodel time series analysis, J. Geophys. Res., 115, D00M10, doi:10.1029/2010JD013857, 2010a.

Austin, J., Struthers, H., Scinocca, J., Plummer, D. A., Akiyoshi, H., Baumgaertner, A. J. G., Bekki, S., Bodeker, G. E., Braesicke, P., Bruhl, C., Butchart, N., Chipperfield, M. P., Cugnet, D., Dameris, M., Dhomse, S., Frith, S., Garny, H., Gettelman, A., Hardiman, S. C., Jockel, P., Kinnison, D., Kubin, A., Lamarque, J. F., Langematz, U., Mancini, E., Marchand, M., Michou, M., Morgenstern, O., Nakamura, T., Nielsen, J. E., Pitari, G., Pyle, J., Rozanov, E., Shepherd, T. G., Shibata, K., Smale, D., Teyssedre, H., and Yamashita Y.: Chemistry-climate model simulations of spring Antarctic ozone, J. Geophys. Res., 115, D00M11, doi:10.1029/2009JD013577, 2010b.

Brönnimann, S. and Hood, L. L.: Frequency of low-ozone events over northwestern Europe in 1952-1963 and 1990-2000, Geophys. Res. Lett., 30, ASC8-1-5, doi:10.1029/2003gl018431, 2003.

Brunner, D., Staehelin, J., Maeder, J. A., Wohltmann, I., and Bodeker, G. E.: Variability and trends in total and vertically resolved stratospheric ozone based on the CATO ozone data set, Atmos. Chem. Phys., 6, 4985-5008, doi:10.5194/acp-6-49852006, 2006.

Butchart, N. and Scaife, A.A. : Removal of chlorofluorocarbons by increased mass exchange between the stratosphere and troposphere in a changing climate, Nature, 410, 799-802, 2001.

Butchart, N., Scaife,, A. A., Bourqui, M., de Grandpre, J., Hare, S. H. E., Kettleborough, J., Langematz, U., Manzini, E., Sassi, F., Shibata, K., Shindell, D., and Sigmond, M.: Simulations of antropogenic change in the strength of the Brewer-Dobson circulation, Clim. Dynam., 27(7-8), 727-41, doi:10.1007/s00382006-0162-4, 2006.

Cressie, N. A. C.: Statistics for Spatial Data. Wiley, New York, revised edition, 1993.

Cressie, N. and Hawkins, D. M.: Robust estimation of the variogram, Int. Assoc. Math. Geol. 12, 115-125, 1980.

Dameris, M., Matthes, S., Deckert, R. Grewe, V., and Ponater, M.: Solar cycle effect delays onset of ozone recovery, Geophys. Res. Lett. 33, L03806 doi:10.1029/2005GL02474, 2006.

Engel, A., Strunk, M., Muller, M., Haase, H. P., Poss, C., Levin, I., and Schmidt, U.: Temporal development of total chlorine in the high-latitude stratosphere based on reference distributions of mean age derived from $\mathrm{CO}_{2}$ and $\mathrm{SF}_{6}$, J. Geophys. Res., 107(D12), 4136, doi:10.1029/2001JD000584, 2002.

Eyring, V., Waugh, D. W., Bodeker, G. E., Cordero, E., Akiyoshi,
H., Austin, J., Beagley, S. R., Boville, B., Braesicke, P., Brühl, C., Butchart, N., Chipperfield, M. P., Dameris, M., Deckert, R., Deushi, M., Frith, S. M., Garcia, R. R., Gettelman, A., Giorgetta, M., Kinnison, D. E., Mancini, E., Manzini, E., Marsh D. R., Matthes, S., Nagashima, T., Newman, P. A., Nielsen, J. E., Pawson, S., Pitari, G., Plummer, D. A., Rozanov, E., Schraner, M., Scinocca, J. F., Semeniuk, K., Shepherd, T. G., Shibata, K., Steil, B., Stolarski, R., Tian, W., and Yoshiki, M.: Multimodel projections of stratospheric ozone in the 21 st century, J. Geophys. Res., 112, D16303, doi:10.1029/2006JD008332, 2007.

Eyring, V., Cionni, I., Bodeker, G. E., Charlton-Perez, A. J., Kinnison, D. E., Scinocca, J. F., Waugh, D. W., Akiyoshi, H., Bekki, S., Chipperfield, M. P., Dameris, M., Dhomse, S., Frith, S. M., Garny, H., Gettelman, A., Kubin, A., Langematz, U., Mancini, E., Marchand, M., Nakamura, T., Oman, L. D., Pawson, S., Pitari, G., Plummer, D. A., Rozanov, E., Shepherd, T. G., Shibata, K., Tian, W., Braesicke, P., Hardiman, S. C., Lamarque, J. F., Morgenstern, O., Pyle, J. A., Smale, D., and Yamashita, Y.: Multi-model assessment of stratospheric ozone return dates and ozone recovery in CCMVal-2 models, Atmos. Chem. Phys., 10, 9451-9472, doi:10.5194/acp-10-9451-2010, 2010.

Farman, J. B., Gardiner, B. G., and Shanklin, J. D.: Large losses of total ozone in Antarctica reveal seasonal, Nature, 315, 207-210, 1985.

Fioletov, V. E., Labow, G., Evans, R., Hare, E. W., Kohler, U., McElroy, C. T., Miyagawa, K., Redondas, A., Savastiouk, V., Shalamyansky, A. M., Staehelin, J., Vanicek, K., and Weber, M.: Performance of ground-based total ozone network assessed using satellite data, J. Geophys. Res., 113, D14313, doi:10.1029/2008JD009809, 2008.

Guillas, S., Stein, M. L., Wuebbles, D. J., and Xia, J.: Using chemistry transport modeling in statistical analysis of stratospheric ozone trends from observations, J. Geophys. Res., 109, D22303, doi:10.1029/2004JD005049, 2004.

Hadjinicolaou, P., Pyle, J., Chipperfield, M. P., and Kettleborough, J.: Effect of interannual meteorological variability on middle latitude $\mathrm{O}_{3}$, Geophys. Res. Lett., 24, 2993-2996, 1997.

Hadjinicolaou, P., Jrrar, A., Pyle, J., and Bishop, L.: The dynamically driven long-term trend in stratospheric ozone over northern middle latitudes, Q. J. Roy. Meteor. Soc., 128, 1393-1412, 2002.

Harris, N. R. P., Kyrö, E., Staehelin, J., Brunner, D., Andersen, S.B., Godin-Beekmann, S., Dhomse, S., Hadjinicolaou, P., Hansen, G., Isaksen, I., Jrrar, A., Karpetchko, A., Kivi, R., Knudsen, B., Krizan, P., Lastovicka, J., Maeder, J., Orsolini, Y., Pyle, J. A., Rex, M., Vanicek, K., Weber, M., Wohltmann, I., Zanis, P., and Zerefos, C.: Ozone trends at northern mid- and high latitudes -a European perspective, Ann. Geophys., 26, 1207-1220, doi:10.5194/angeo-26-1207-2008, 2008.

Hegglin, M. I. and Shepherd, T. G.: Large climate-induced changes in UV index and stratosphere-to-troposphere ozone flux, Nat. Geosci., 2, 687-691, 2009.

Hood, L. L. and Zaff, D. A.: Lower stratospheric stationary waves and the longitude dependence of ozone trends in winter, J. Geophys. Res.-Atmos., 100, 25791-25800, 1995.

Hood, L. L. and Soukharev, B. E.: Interannual Variations of Total Ozone at Northern Midlatitudes Correlated with Stratospheric EP Flux and Potential Vorticity, J. Atmos. Sci., 62, 3724-3740, 2005.

Krizan, P. and Lastovicka, J.: Trends in positive and negative ozone 
laminae in the Northern Hemisphere, J. Geophys. Res., 110, D10107, doi:10.1029/20004JD005477, 2005.

Labitzke, K. and Van Loon, H.: The Stratosphere, Springer, 179 pp., 1999.

Li, F., Stolarski, R. S., and Newman, P. A.: Stratospheric ozone in the post-CFC era, Atmos. Chem. Phys., 9, 2207-2213, doi:10.5194/acp-9-2207-2009, 2009.

Mäder, J. A., Staehelin, J., Brunner, D., Stahel, W. A., Wohltmann, I., and Peter, T.: Statistical modeling of total ozone: Selection of appropriate explanatory variables, J. Geophys. Res, 112, D11108, doi:10.1029/2006JD007694, 2007.

McLandress, C. and Shepherd, T. G.: Simulated anthropogenic changes in the Brewer-Dobson circulation, including its extension to higher latitudes, J. Clim., 22, 1516-1540, 2009.

Molina M. J. and Rowland, F. S.: Stratospheric sink for chlorofluoromethanes: chlorine atom-catalysed destruction of ozone, Nature, 249, 810-812, 1974.

Montzka, S. A., Butler, J. H., Myers, R. C., Thompson, T. M., Swanson, T. H., Clarke, A. D., Lock, L. T., and Elkins, J. W.: Decline in tropospheric abundance of halogen from halocarbons: Implications for stratospheric ozone depletion, Science 272, 1318-1322, 1996.

Morgenstern, O., Braesicke, P., Hurwitz, M. M., O’Connor, F. M., Bushell, A. C., Johnson, C. E., and Pyle, J. A.: The world avoided by the Montreal Protocol, Geophys. Res. Lett., 35, L16811, doi:10.1029/2008g1034590, 2008.

Newchurch, M. J., Yang, E. S., Cunnold, D. M., Reinsel, G. C., Zawodny, J. M., and Russell, J. M.: Evidence for slowdown in stratospheric ozone loss: First stage of ozone recovery, J. Geophys. Res., 108, 4507, ACH12-1-13, 2003.

Newman, P. A., Nash, E. R., Kawa, S. R., Montzka, S. A., and Schauffler, S. M.: When will the Antarctic ozone hohle recover?, Geophys. Res. Lett., 33, L12814, doi:10.1029/2005GL025232, 2006.

Newman, P. A., Daniel, J. S., Waugh, D. W., and Nash, E. R.: A new formulation of equivalent effective stratospheric chlorine (EESC), Atmos. Chem. Phys., 7, 4537-4552, doi:10.5194/acp7-4537-2007, 2007.

Newman, P. A., Oman, L. D., Douglass, A. R., Fleming, E. L., Frith, S. M., Hurwitz, M. M., Kawa, S. R., Jackman, C. H., Krotkov, N. A., Nash, E. R., Nielsen, J. E., Pawson, S., Stolarski, R. S., and Velders, G. J. M.: What would have happened to the ozone layer if chlorofluorocarbons (CFCs) had not been regulated?, Atmos. Chem. Phys., 9, 2113-2128, doi:10.5194/acp-9-2113-2009, 2009.

Orsolini, Y. and Doblas-Reyes, F.: Ozone signatures of climate patterns over the Euro-Atlantic sector in the spring, Q. J. Roy. Meteor. Soc., 595, 3251-3263, 2003.

Percival, D. B. and Rothrock, D. A.: "Eyeballing" trends in climate time series: A coautionary note, J. Climate, 18, 886-891, 2005.

Peter, T.: Microphysics and heterogeneous chemistry of polar stratospheric clouds, Annu. Rev. Phys. Chem., 48, 785-822, 1997.

Prather, M., Midgley, P., Rowland, F. S., and Stolarski, R.: The ozone layer: The road not taken, Nature, 381, 551-554, 1996.

Randel, W., Wu, F., Russell, J., Waters, J., and Froidevaux, L.: Ozone and temperature-changes in the stratosphere following the eruption of Mount-Pinatubo, J. Geophys. Res, 100, 16753$16764,1995$.
Reinsel, G. C., Weatherhead, E. C., Tiao, G. C., Miller, A. J., Nagatani, R. M., Wuebbles, D. J., and Flynn, L. E.: On detection of turnaround and recovery in trend for ozone, J. Geophys. Res. 107, 4078, 2002.

Reinsel, G. C.: Trend analysis of upper stratospheric Umkehr ozone data for evidence of turnaround, Geophys. Res. Lett., 29, 1451, doi:10.1029/2002GL014716, 2002.

Reinsel, G. C., Miller, A. J., Weatherhead, E. C., Flynn, L. E., Nagatani, R. M., Tiao, G. C., and Wuebbles, D. J.: Trend analysis of total ozone data for turnaround and dynamical contributions, J. Geophys. Res. 110, D16306, doi:10.1029/2004JD004662, 2005.

Rieder, H. E., Staehelin, J., Maeder, J. A., Peter, T., Ribatet, M., Davison, A. C., Stübi, R., Weihs, P., and Holawe, F.: Extreme events in total ozone over Arosa - Part 2: Fingerprints of atmospheric dynamics and chemistry and effects on mean values and long-term changes, Atmos. Chem. Phys., 10, 10033-10045, doi:10.5194/acp-10-10033-2010, 2010.

Rinsland, C. P., Mahieu, E., Zander, R., Jones, N. B., Chipperfield, M. P., Goldman, A., Anderson, J., Russell, J. M., III, Demoulin, P., Notholt, J., Toon, G. C., Blavier, J.-F., Sen, B., Sussmann, R., Wood, S. W., Meier, A., Griffith, D. W. T., Chiou, L. S., Murcray, F. J., Stephen, T. M., Hase, F., Mikuteit, S., Schulz, A., and Blumenstock, T.: Long-term trends of inorganic chlorine from ground-based infrared solar spectra: Past increases and evidence for stabilization, J. Geophys. Res., 108, 4252, doi:10.1029/2002JD003001, 2003.

Robock, A.: Volcanic eruptions and climate, Rev. Geophys., 38, 191-219, 2000.

Robock, A., Adams, T., Moore, M., Oman, L., and Stenchikov, G.: Southern Hemisphere atmospheric circulation effects on th 1991 Mount Pinatubo Eruption, Geophys. Res. Lett., 34(23), L23710, doi:10.1029/2007GL031403, 2007.

Rosenfield, J. E., Considine, D. B., Meade, P. E., Bacmeister, J. T., Jackman, C. H., and Schoeberl, M. R.: Stratospheric effects of Mount Pinatubo aerosol studied with a coupled two-dimensional model, J. Geophys. Res., 102(D3), 3649-3670, 1997.

Shepherd, T. G.: Dynamics, stratospheric ozone, and climate change, Atmos.-Ocean, 46, 371-392, 2008.

Solomon, S.: Stratospheric ozone depletion: A review of concepts and history, Rev. Geophys., 37, 275-316, 1999.

Solomon, S., Portmann, R. W., and Thompsom, D. W. J.: Contrasts between Antarctic and arctic ozone depletion, Proceedings of the national academy of science of the untired states of Americam 104, 445-449, 2007.

SPARC-CCMVal: SPARC Report on the Evaluation of ChemistryClimate Models, 2010.

Staehelin, J., Harris, N. R. P., Appenzeller, C., and Eberhard, J.: Ozone trends: A review, Rev. Geophys., 39, 231-290, 2001.

Staehelin, J., Mäder, J., Weiss, A. K., and Appenzeller, C.: Longterm ozone trends in Northern mid-latitudes with special emphasis on contribution of changes in dynamics, Phys. Chem. Earth (B), 27, 461-469, 2002.

Steinbrecht, W., Claude, H., Kohler, U., and Hoinka, K. P.: Correlations between tropopause height and total ozone: Implications for long-term changes, J. Geophys. Res.-Atmos., 103(D15), 19183-19192, 1998.

Steinbrecht, W., Claude, H., and Winkler, P.: Enhanced upper stratospheric ozone: Sign of recovery or solar cycle effect?, J. Geophys. Res., 109, D02308, doi:10.1029/2003JD004284, 2004. 
Stolarski, R. S. and Cicerone, R. J.: Stratospheric chlorine: a possible sink for ozone, Can. J. Chem. 52, 1610-1615, 1974.

Thompson, D. W. J. and Wallace, J. M.: Annular modes in the extratropical circulation. Part I: Month-to-month variability, J. Climate, 13, 1000-1016, 2000.

Velders, G. J. M., Andersen, S. O., Daniel, J. S., Fahey, D. W., and McFarland, M.: The importance of the Montreal Protocol in protecting climate, Proc. Natl. Acad. Sci. USA, 104, 4814-4819, doi:10.1073/pnas.0610328104, 2007.

Waugh, D. W., L., Oman, S. R., Kawa, R. S., Stolarski, S., Pawson, A. R., Douglass, P. A., Newman, and Nielsen, J. E.: Impacts of climate change on stratospheric ozone recovery, Geophys. Res. Lett., 36(3), L03805, doi:10.1029/2008GL036223, 2009.

Weatherhead, C. and Anderson, S. B.: The search for signs of recovery of the ozone layer, Nature, 441, 39-45, doi:10.1038/nature04746, 2006.

Weatherhead, E. C., Reinsel, G. C., Tiao, G. C., Jackman, C. H., Bishop, L., Frith. S. M. H., DeLuisi. J., Keller, T., Oltmans, S. J., Fleming, E. L., Wuebbles, D. J., Kerr, J. B., Miller, A. J., Herman, J., McPeters, R., Nagatani, R. M., and Frederick, J. E.: Detecting the recovery of total column ozone, J. Geophys. Res. 105, 22201-22210, 2000.
Wohltmann, I., Rex, M., Brunner, D., and Mäder, J.: Integreated equivalent latitude as a proxy for dynamical changes in ozone column, Geophys. Res. Lett., 32, L09811, doi:10.1029/2005GL022497, 2005.

World Meteorological Organisation, Report of the International Ozone Trends Panel 1988, Rep. 18, Global Ozone Research and Monitoring Project, Geneva, 1989.

World Meteorological Organisation, WMO Antarctic ozone bulletin 7, available at: http://www.wmo.ch/pages/prog/arep/ gawozobull06_en.html, 2006.

World Meteorological Organisation. Scientific Assessment of Ozone Depletion: 2006, Rep. 50, Global Ozone Research and Monitoring Project, Geneva, 2007.

Yang, E. S., Cunnold, D. M., Newchurch, M. J., and Salawitch, R. J.: Change in ozone trends at southern high latitudes, Geophys. Res. Lett., 32, L12812, doi:10.1029/2004GL02296, 2005.

Yang, E.-S., Cunnold, D. M., Salawitch, R. J., McCormick, M. P., Russell, J., Zawodny III, J. M., Oltmans, S., and Newchurch, M. J.: Attribution of recovery in lower-stratospheric ozone, J. Geophy. Res., 111, D17309, doi:10.1029/2005JD006371, 2006. 